\title{
General modulation transfer function fitting equation for human eye with contact lens
}

\author{
Faten Sh. Zainulabdeen ${ }^{1,{ }^{*}}$, Mohammed A. Hussein ${ }^{2}$, Ail H. AL-Hamdani ${ }^{3}$ \\ ${ }^{1}$ Dept. of Physics, College of Education, Mustansiriyah University, Baghdad, Iraq \\ ${ }^{2}$ Dept. of Electrical Engineering, University of Technology, Baghdad, Iraq \\ ${ }^{3}$ Laser and Optoelectronics Engineering Dept. University of Technology, Baghdad, Iraq \\ ${ }^{*}$ Corresponding author:dr.fatenshkour@uomustansiriyah.edu.iq
}

\begin{abstract}
In this research, a general equation was derived to represent the modulation transfer function (MTF) of the human eye with the presence of the contact lenses (CL) and during the vision with monochrome or multi-wavelength (polychromatic) light. This equation was used to fit the MTF's curves for the eye with pupil diameters (EPD) $(2.5,4,6$, and $8 \mathrm{~mm})$. The fitting equation accuracy was revealed by using the standard deviation (STD). The results indicated that the image MTF is sensitive to (EPD). Moreover, eye vision degrades as (EPD) increases due to the increased spherical and chromatic aberrations. The new equation consists of two exponential terms in addition to a correction polynomial function $(\mathrm{H})$ to fit the EPD effect. The results showed that $\mathrm{H}$ function with power two is sufficient to give a good accuracy when the EPD is less than $4 \mathrm{~mm}$, while $\mathrm{H}$ with power five is necessary when the EPD is larger or equal to $5 \mathrm{~mm}$. The equation gives a high accuracy also in the case of vision with white light for the eye with a contact lens.
\end{abstract}

Keywords: Contact lenses; eye vision; fitting equation; image analysis; MTF.

\section{Introduction}

The human eye works as a complex refractive optical system consisting of the cornea, the anterior chamber, the crystalline lens, and finally the retina. This composition works together to form high images quality. Several models have predestined the human eye (Schulz, 2009), evaluated and analyzed the optical performance of eye and weak image boundaries(Almeida \& Carvalho, 2007; Gharsallah \& Braiek, 2017; Navarro et al., 2006). The closest schematic eye model to the biological eye is Liou and Brennan's model (LBM). They suggested an aspherical gradient refractive index cornea and crystalline lens(Liou \& Brennan, 1997; Liu et al., 2005). Cataract surgeries (intraocular lens implementation), specular lens, and contact lens (CL)(Walsh \& Charman, 1988; Watson, 2013) are used for visioncorrecting(Bope \& Kellerman, 2015).
Hybrid Diffractive/Refractive multi-focal intraocular lenses Implanted within human eyes were designed and evaluated by (AlHamdani, 2021). Material types selection used in optical elements fabricating is fundamental to obtain an ideal lens to correct the refractive errors. Early optical elements such as CL were made of glass; afterward, organic materials have been utilized to manufacture them (Efron, 2010; Walsh \& Charman, 1988). Polymeric materials used in processing the vision correction elements are prescribed by several factors, such as flexibility of prepared film, transparency, gas and water permeability, diaphanous thermoplastics, such as polysulfones (PSU), polyethersulfones, and polypherylsulfones, preserve constant strength, hardness, and hydrolytic resistance and within a wide range 
of variations in temperature values (Sastri, 2013).

\section{Theory}

The most important criterion is called modulation transfer function (MTF) in studding the optical system analysis and image quality. MTF is a criterion used to demonstrate eye vision or any optical system performance. The MTF is explained as the Fourier transform of the optical point spread function (PSF). MTF, at a specific frequency $(v)$ denoted by $\operatorname{MTF}(v)$, is defined as the modulation of the image $\left(M_{i}\right)$ divided by the modulation of the object $\left(M_{o}\right)$, and is expressed as follows:

$$
\operatorname{MTF}(v)=\frac{M_{i}}{M_{o}}
$$

For a perfect optical system, which is one with negligible aberration effects, the MTF is stated by:

$$
\operatorname{MTF}_{\operatorname{diffr}(v)=\frac{2}{\pi}\left[\cos ^{-1}(\omega)-(\omega) \sqrt{1-\omega^{2}}\right]}
$$

Where,

$\omega$ is the normalized spatial frequency $=$ $\frac{v}{v_{0}} ; \quad v$ is the spatial frequency $($ cycle $/ \mathrm{mm})$,

$v_{0}=\frac{1}{\lambda F \#}$ is the cut-off frequency

$\lambda$ is the wavelength and $F \#$ is the f-number.

Equation (2) is applied to an optical system with a circular aperture.

The calculation of the geometric MTF assumes a perfect optical system and judges the performance of a lens as a function of defocus. Diffraction effects are ignored. This assumption leads to (Haines \& King, 1968; Shannon, 1994).

$$
\operatorname{MTF}_{\text {geom }}(v)=\frac{2 J_{1}\left[\frac{\pi v \delta}{F^{\#}}\right]}{\frac{\pi v \delta}{\left(F^{\#}\right)}}
$$

With $J_{1}$ the first-order Bessel function and $\delta$ is the defocusing error.

Human eye entrance pupil diameter (EPD) impact on the performance of the retinal image MTF for eyes without CLs and under monochromatic light effect was studied(AlHamdani, 2018; Al-Hamdani, 2021). This article is based on Liou and Brennan's model (LBM) to design the human eye with a contact lens by using the zemax-premium 13 optical design program, (the design lens data editor was in Al-hamdani, 2020). The study was done in the presence of PSU-CLs and their influences on the MTF behavior for monochromatic $555 \mathrm{~nm}$ and polychromatic light $(470,510,550,610,650) \mathrm{nm}$ with weights of $(0.091,0.503,0.503$, and 0.107$)$, respectively. An analytical fitting equation was evaluated. A general fitting equation for the MTF for the eye with and without CL, in white and monochromatic vision, was evaluated and analyzed. The accuracy of the fitting equation was studied by calculating the stranded error for each case.

\section{Fitting formulas for the MTF}

Many equations have been developed to represent the practical data, especially for the monochromatic light state (Bäumer, 2011). Initially, single functions were used, such as exponentials or Gaussians (Campbell \& Gubisch, 1966; Dai, 2008; Flamant, 1955; Krueger \& EA, 1973; Malacara et al., 2004; Shannon \& Wyant, 1992; Wetherell, 1980), which were not very precise to the experiment data. More recently, approximations with just two parameters (exponential functions) were submitted (Deeley et al., 1991). These expressions provided a good fit at low and intermediate spatial frequencies but they were with a poor accuracy at high frequencies. By incorporating the EPD as a parameter in the expressions.

MTF would be described easily for any given pupil diameter. All of the preceding author's aims in this field were to introduce an accurate parametric model to describe the ocular MTF for every pupil size. The fitting for polychromatic MTF light is more complicated than monochromatic one, since the cut-off frequency depends on the wavelength, as shown in equation (3). In this work, the aim is to obtain a new general 
analytical MTF equation ( by using Fortan 77), that can fit all the cases (monochromatic, polychromatic vision with and without $\mathrm{CL}$ ).

\section{Results and discussions}

The new general equation obtained in this work consists of two exponential functions and a correction polynomial function called error function $(\mathrm{H})$ used only for high accurate fitting and for EPD larger than 5 $\mathrm{mm}$. The new analytical expression allows calculating the MTF function as a function of spatial frequency and EPD for monochromatic and polychromatic light vision. This general analytical equation is expressed as:

$$
\mathrm{MTF}=G e^{-B_{0} v d^{2}}+(1-G) e^{-A_{0} v d^{2}}+H
$$$$
F=\left(C_{1}-C_{2} d^{2}\right)
$$

$H=$ Error function $=p_{0}+p_{1} v+$

$$
p_{2} v^{2}+p_{3} v^{3}+p_{4} v^{4}+\cdots p_{i} v^{i}
$$

Where $d$ is the entrance pupil diameter (EPD): $p_{i}$ is the polynomial parameters: $A_{0}=0.0022: B_{0}=0.00235: C_{1}=-14.25$ and $C_{2}=-$ 0.13 are constants. This equation was applied and analyzed in the following four optical cases:

Case 1: MTF equation for the eye without $\mathrm{CL}$ in monochromatic light vision.

The predictions of the general formula are shown along with the MTFs for each pupil diameter $(2.5,4,6$, and 8) for eyes without contact lenses in Figure 1. These fits are reasonably good with a given zero or low standard error for EPD 2 to $4 \mathrm{~mm}$ and the equation with a small number of terms (only three terms) is required. The fitting with five terms is necessary for EPD $>4 \mathrm{~mm}$. Table 1 shows the values of the parameters in the correct function $\mathrm{H}$ in equation 7 and the low standard deviation between 0.0 and 0.004 .

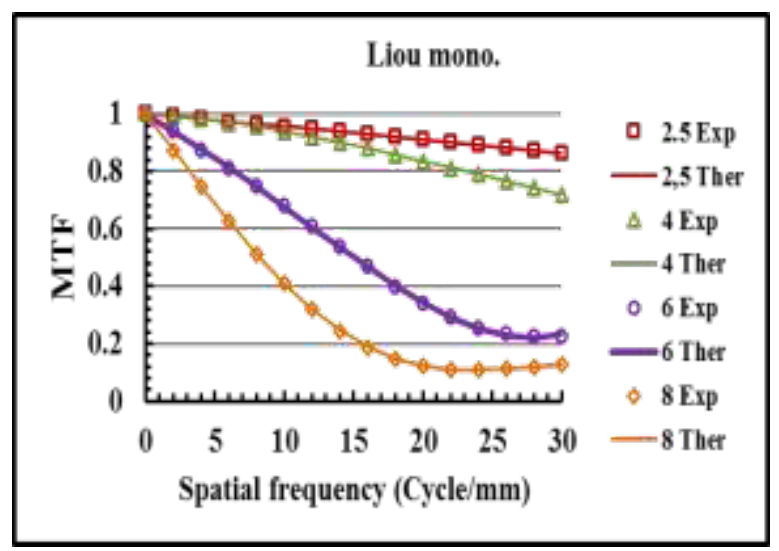

Fig. 1. Experimental (LBM) MTF (Exp) and the theoretical (Ther) from the fitting of equation (6) for the eye without contact lens in monochromatic light.

A similar Figures 2, 3, and 4 and Tables 2,3 , and 4 are illustrated for the following three cases respectively as follows:

Case 2: MTF equation for the eye without $\mathrm{CL}$ in polychromatic light vision .

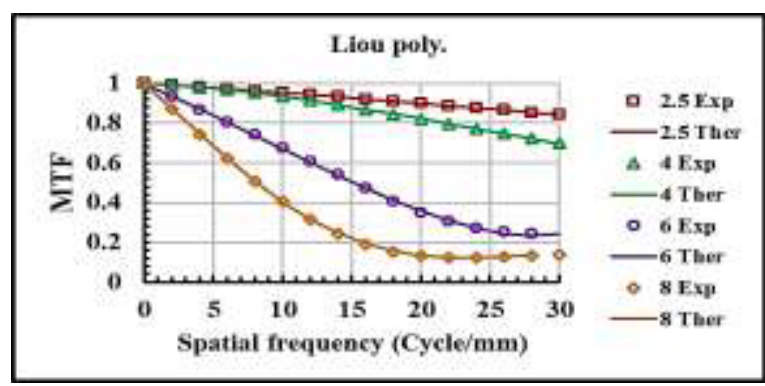

Fig. 2. Experimental (LBM) MTF (Exp) and the theoretical (Ther) from the fitting of equation (6) for the eye without contact lens in polychromatic light.

Case 3: MTF equation for the eye with CL in monochromatic light vision.

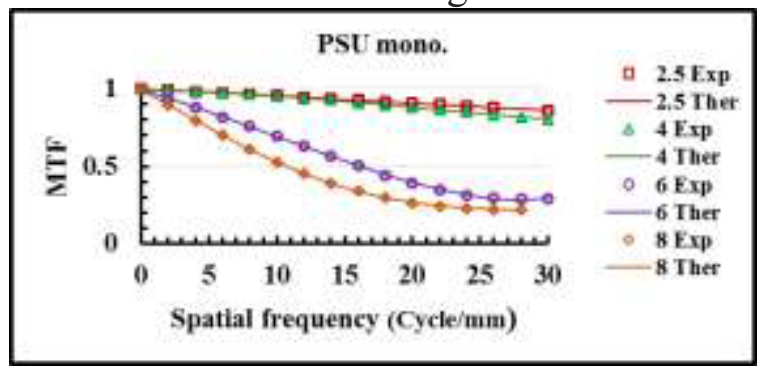

Fig. 3. Experimental (LBM) MTF (Exp) and the theoretical (Ther) from the fitting of equation (6) for the eye with CL in monochromatic light. 
Case 4: MTF equation for the eye with CL in polychromatic light vision.

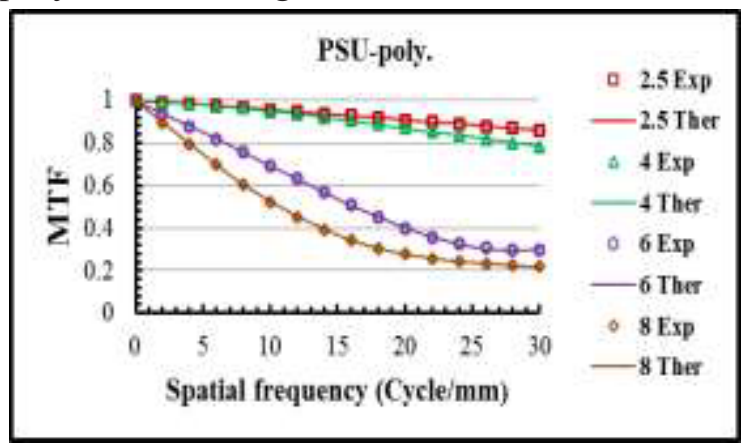

Fig. 4. Experimental (LBM) MTF (Exp) and the theoretical (Ther) from the fitting of equation (6) for the eye with CL in polychromatic light.
From all the four cases results in Figures 1-4 and Tables 1-4, one can observe that for a small EPD (0-4 mm), the fitting accuracy is reasonably well with only three terms of the correction function $\mathrm{H}$ (equation 7). While for $\mathrm{EDP}>4 \mathrm{~mm}$, the same fitting equation 6 gives an accurate fitting with 5 terms. The fitting equation used in this work consists of two exponential functions and a new correction function $\mathrm{H}$ to the generalized equation 6 for all pupil diameters in the moonlight and white light. The generalization of the equation to include white light is more complicated since the cut-off frequency depends on wavelength. The fit equation is prober for low, midrate, and high spatial frequencies.

Table 1. The P's parameters value and standard deviation for each EPD in monochromatic light without CL.

\begin{tabular}{ccccccc}
\hline $\begin{array}{c}\text { EPD } \\
\mathbf{m m}\end{array}$ & $\mathbf{P}_{\mathbf{0}}$ & $\mathbf{P}_{\mathbf{1}}$ & $\mathbf{P}_{\mathbf{2}}$ & $\mathbf{P}_{\mathbf{3}}$ & $\mathbf{P}_{\mathbf{4}}$ & ST Dev. \\
\hline 2.5 & $5.76 \mathrm{E}-04$ & $2.90 \mathrm{E}-03$ & $-4.44 \mathrm{E}-05$ & & & 0 \\
\hline 3 & $1.07 \mathrm{E}-03$ & $9.89 \mathrm{E}-04$ & $-5.21 \mathrm{E}-05$ & & & 0 \\
\hline 4 & $2.21 \mathrm{E}-03$ & $-4.02 \mathrm{E}-03$ & $4.87 \mathrm{E}-05$ & & & 0.001 \\
\hline 5 & $3.37 \mathrm{E}-03$ & $-7.80 \mathrm{E}-03$ & $2.63 \mathrm{E}-07$ & $3.18 \mathrm{E}-05$ & $-7.66 \mathrm{E}-07$ & 0.003 \\
\hline 6 & $4.02 \mathrm{E}-03$ & $-1.11 \mathrm{E}-03$ & $-1.96 \mathrm{E}-04$ & $4.46 \mathrm{E}-05$ & $-1.24 \mathrm{E}-06$ & 0.004 \\
\hline 7 & $8.37 \mathrm{E}-04$ & $1.24 \mathrm{E}-02$ & $8.52 \mathrm{E}-04$ & $-1.18 \mathrm{E}-04$ & $2.38 \mathrm{E}-06$ & 0.003 \\
\hline 8 & $2.98 \mathrm{E}-03$ & $-2.66 \mathrm{E}-02$ & $3.81 \mathrm{E}-03$ & $-1.71 \mathrm{E}-04$ & $2.35 \mathrm{E}-06$ & 0.002 \\
\hline
\end{tabular}

Table 2. The P's parameters value and standard deviation for each EPD in polychromatic light without CL.

\begin{tabular}{ccccccc}
\hline $\begin{array}{c}\text { EPD } \\
\mathbf{m m}\end{array}$ & $\mathbf{P}_{\mathbf{0}}$ & $\mathbf{P}_{\mathbf{1}}$ & $\mathbf{P}_{\mathbf{2}}$ & $\mathbf{P}_{\mathbf{3}}$ & $\mathbf{P}_{\mathbf{4}}$ & ST Dev \\
\hline 2.5 & $3.69 \mathrm{E}-04$ & $3.08 \mathrm{E}-03$ & $-2.98 \mathrm{E}-05$ & & & 2.5 \\
\hline 3 & $7.81 \mathrm{E}-04$ & $1.24 \mathrm{E}-03$ & $-3.56 \mathrm{E}-05$ & & & 3 \\
\hline 4 & $1.14 \mathrm{E}-03$ & $-3.25 \mathrm{E}-03$ & $4.71 \mathrm{E}-05$ & & & 4 \\
\hline 5 & $4.33 \mathrm{E}-03$ & $-7.78 \mathrm{E}-03$ & $1.33 \mathrm{E}-04$ & $2.34 \mathrm{E}-05$ & $-6.54 \mathrm{E}-07$ & 5 \\
\hline 6 & $4.00 \mathrm{E}-03$ & $1.20 \mathrm{E}-03$ & $-4.33 \mathrm{E}-04$ & $4.82 \mathrm{E}-05$ & $-1.20 \mathrm{E}-06$ & 6 \\
\hline 7 & $-1.21 \mathrm{E}-03$ & $1.61 \mathrm{E}-02$ & $2.04 \mathrm{E}-04$ & $-8.85 \mathrm{E}-05$ & $1.99 \mathrm{E}-06$ & 7 \\
\hline 8 & $2.53 \mathrm{E}-03$ & $-2.53 \mathrm{E}-02$ & $3.76 \mathrm{E}-03$ & $-1.77 \mathrm{E}-04$ & $2.53 \mathrm{E}-06$ & 8 \\
\hline
\end{tabular}


Table 3. The P's parameters value and standard deviation for each EPD in monochromatic light with CL.

\begin{tabular}{rcccccc}
\hline $\begin{array}{c}\text { EPD } \\
\mathbf{m m}\end{array}$ & $\mathbf{P}_{\mathbf{0}}$ & $\mathbf{P}_{\mathbf{1}}$ & $\mathbf{P}_{\mathbf{2}}$ & $\mathbf{P}_{\mathbf{3}}$ & $\mathbf{P}_{\mathbf{4}}$ & ST Dev. \\
\hline 2.5 & 0.000576 & 0.002897 & $-4.4 \mathrm{E}-05$ & & & 0 \\
\hline 3 & 0.001545 & 0.000647 & $-7.4 \mathrm{E}-05$ & & & 0.001 \\
\hline 4 & 0.00401 & -0.00506 & $-1.6 \mathrm{E}-05$ & & & 0.002 \\
\hline 5 & 0.002798 & -0.00838 & -0.00017 & $3.19 \mathrm{E}-05$ & $-6.8 \mathrm{E}-07$ & 0.002 \\
\hline 6 & 0.003496 & -0.0019 & -0.00031 & $4.45 \mathrm{E}-05$ & $-1.2 \mathrm{E}-06$ & 0.004 \\
\hline 7 & 0.001143 & -0.00225 & 0.000418 & $-3.3 \mathrm{E}-05$ & $5.5 \mathrm{E}-07$ & 0.001 \\
\hline 8 & 0.001883 & -0.03727 & 0.003211 & -0.00011 & $1.34 \mathrm{E}-06$ & 0.001 \\
\hline
\end{tabular}

Table 4. The P's parameters value and standard deviation for each EPD in polychromatic light with CL

\begin{tabular}{ccccccc}
\hline $\begin{array}{c}\mathbf{E P D} \\
\mathbf{m m}\end{array}$ & $\mathbf{P}_{\mathbf{0}}$ & $\mathbf{P}_{\mathbf{1}}$ & $\mathbf{P}_{\mathbf{2}}$ & $\mathbf{P}_{\mathbf{3}}$ & $\mathbf{P}_{\mathbf{4}}$ & ST Dev. \\
\hline 2.5 & $6.30 \mathrm{E}-04$ & $2.84 \mathrm{E}-03$ & $-4.05 \mathrm{E}-05$ & & & 0 \\
\hline 3 & $1.42 \mathrm{E}-03$ & $7.97 \mathrm{E}-04$ & $-6.12 \mathrm{E}-05$ & & & 0.001 \\
\hline 4 & $3.45 \mathrm{E}-03$ & $-4.62 \mathrm{E}-03$ & $-8.96 \mathrm{E}-06$ & & & 0.001 \\
\hline 5 & $3.42 \mathrm{E}-03$ & $-8.43 \mathrm{E}-03$ & $-5.57 \mathrm{E}-05$ & $2.56 \mathrm{E}-05$ & $-5.98 \mathrm{E}-07$ & 0.003 \\
\hline 6 & $3.63 \mathrm{E}-03$ & $-6.45 \mathrm{E}-04$ & $-3.97 \mathrm{E}-04$ & $4.25 \mathrm{E}-05$ & $-1.05 \mathrm{E}-06$ & 0.004 \\
\hline 7 & $1.47 \mathrm{E}-04$ & $5.97 \mathrm{E}-04$ & $8.21 \mathrm{E}-05$ & $-2.42 \mathrm{E}-05$ & $5.08 \mathrm{E}-07$ & 0.001 \\
\hline 8 & $1.15 \mathrm{E}-03$ & $-3.50 \mathrm{E}-02$ & $3.01 \mathrm{E}-03$ & $-1.11 \mathrm{E}-04$ & $1.42 \mathrm{E}-06$ & 0.001 \\
\hline
\end{tabular}

\section{Conclusion}

The influence of the EPD on the quality of the human eye image with contact lens (CL) is demonstrated. Results revealed that, with a EPD of $8 \mathrm{~mm}$, increasing the opening of the pupil can reduce the image clarity and cause a lack of vision because the aberrations are largest. Aberrations are absent at the lens opening size radius of $2.5 \mathrm{~mm}$. The use of CL substantially improves the vision quality. The degradation caused by pupil size is reduced, thereby improving the performance of the eye, especially for polychromatic vision. The fitting equation with EPD less than $4 \mathrm{~mm}$ gives a small STD by using only three terms from the correction polynomial H. Five terms are necessary for high accuracy with EPD $>4 \mathrm{~mm}$. In this work, the resulted equation with two exponential functions and a corrected function can be used to determine the MTF for monochromatic and polychromatic eye vision for different pupil diameters with zero or small error.

\section{ACKNOWLEDGMENTS}

The authors would like to thank the Mustansiriyah University (www.uomustan siriyah.edu.iq) and the University of Technology (www.uotechnology.edu.iq) Baghdad-Iraq, for their support in the present work.

\section{References}

Al-Hamdani, A. H (2018). Design and Performance Analysis of Contact Lens Materials for Chromatic and Polychromatic Aberrations Correction. Engineering and Technology Journal 36: 1016-1021. 
Al-Hamdani, A. H., Hashim, H. T., and Rashid, H. G. (2021). Optimum design of the hybrid (diffractive/refractive) multifocal intraocular lenses implanted within the human eye. Kuwait Journal of Science 48.

Almeida, M. S. d., and Carvalho, L. A. (2007). Different schematic eyes and their accuracy to the in vivo eye: a quantitative comparison study. Brazilian Journal of Physics 37: 378-387.

Bäumer, S. (2011). Handbook of plastic optics: John Wiley \& Sons).

Bope, E. T., and Kellerman, R. D. (2015). Conn's current therapy 2016: Elsevier Health Sciences).

Campbell, F., and Gubisch, R. (1966). The optical quality of the human eye. The Journal of physiology 186: 558-578.

Dai, G.-m. (2008). Wavefront optics for vision correction, Vol 179: SPIE press).

Deeley, R. J., Drasdo, N., and Charman, W. N. (1991). A simple parametric model of the human ocular modulation transfer function. Ophthalmic and Physiological Optics 11: 91-93.

Efron, N. (2010). Contact Lens Practice. (2nd ed.). Butterworth-Heinemann / Elsevier, Oxford, Uk; St Louis, Mo.

Flamant, F. (1955). Étude de la répartition de lumière dans l'image rétinienne d'une fente. Revue d'Optique théorique et instrumentale.

Gharsallah, M. B., and Braiek, E. B. (2017). New anisotropic diffusion method to improve radiographic image quality. Kuwait Journal of Science 44.

Haines, J. H., and King, J. P. (1968). Approximate computations of physical MTF. Paper presented at Modulation Transfer
Function (International Society for Optics and Photonics).

Krueger, H., and EA, M. (1973). On the approximation of the optical modulation transfer function (MTF) by analytical functions.

Liou, H.-L., and Brennan, N. A. (1997). Anatomically accurate, finite model eye for optical modeling. JOSA A 14: 1684-1695.

Liu, Y.-J., Wang, Z.-Q., Song, L.-P., and Mu, G.-G. (2005). An anatomically accurate eye model with a shell-structure lens. Optik 116: $241-246$.

Malacara, D., Malacara, Z., and Malacara, D. (2004). Handbook of optical design (pp. 378-380). New York, NY: Marcel Dekker.

Navarro, R., González, L., and Hernández-Matamoros, J. L. (2006). On the prediction of optical aberrations by personalized eye models. Optometry and Vision Science 83: 371-381.

Sastri, V. R. (2013). Plastics in medical devices: properties, requirements, and applications: William Andrew).

Schulz, M. N. (2009). Progress in Optics Research: Nova Science Publishers).

Shannon, R. (1994). A useful optical engineering approximation. Optics and Photonics News 5: 34.

Shannon, R. R., and Wyant, J. C. (1992). Applied optics and optical engineering, Volume XI. Applied Optics and Optical Engineering, Volume XI 11.

Walsh, G., and Charman, W. (1988). The effect of pupil centration and diameter on ocular performance. Vision Research 28: 659-665. 
Watson, A. B. (2013). A formula for the mean human optical modulation transfer function as a function of pupil size. Journal of Vision 13: 18-18.

Wetherell, W. B. (1980). The calculation of image quality. In Applied optics and optical engineering, (Elsevier), pp. 171-315.

Submitted:

$13 / 07 / 2020$

Revised:

$19 / 10 / 2020$

Accepted:

$24 / 10 / 2020$

DOI:

10.48129/kjs.v48i4.10089 